\title{
DIE GEBEUKTE KIND
}

\author{
Margaretha C. van Huyssteen \\ Professor en Hoof, Departement Verpleegkunde, \\ Randse Afrikaanse Universiteit
}

\section{SUMMARY}

The nurse, and especially the midwife and community health nurse, can make a major contribution towards the prevention of child abuse by developing a sensitivity in respect of the contributing factors which make of a parent a potential abuser of children, by helping to identify these parents, by giving the necessary assistance and guidance and by providing sources of reference where necessary.

$\mathbf{S}$ edert Caffey in 1946 die verband tussen subdurale hematome en frakture in langbene by jong kinders beskryf het en navorsers ' $n$ dekade later bevind het dat sulke beserings deur ouers veroorsaak kan word, is daar 'n groeiende belangstelling in geweldadige beserings by jong kinders.

Die emosiebelaaide term "Battered Child Syndrome" het sy oorsprong gekry en aanleiding gegee tot grootskaalse navorsing waarna moontlike oorsake beskryf is en riglyne vir behandeling opgetrek is. In sommige lande het dit gelei tot verpligte aanmelding van mishandeling van kinders.

Alhoewel daar bewyse is dat sulke beserings in dié lande in getalle afgeneem het, neem die mensdom telkens met groeiende kommer die herhaling van die verskynsel waar. Elke keer as die koerante met groot vet letters en op dramatiese wyse die aandag vestig op nog 'n kind wat op een of ander wyse wreed deur 'n ouer of ouers mishandel is, gaan daar 'n skokgolf deur die gemeenskap. Die lafhartige daad vul iedereen met afsku en met ' $n$ amper hulpelose, patetiese jammerte vir die weerlose slagoffertjie.

Gedurende 1979 moes Suid-Afrika lees van die dood van 'n dogtertjie na herhaalde ernstige beserings toegedien oor 'n lang tydperk deur 'n man wat uiteindelik die hoogste tol vir sy dade moet betaal. 'n Mens vra jouself af hoe so iets kon gebeur. Waar was die bure? Het niemand dan ooit onraad gemerk nie en indien wel, soos uit latere getuies geblyk het, hoekom het niemand iets gedoen om die mishandeling stop te sit nie? Die skynbare totale onbetrokkenheid van die gemeenskap in dié geval skreeu ten hemele.

Die vraag is of ons as verpleegkundiges 'n positiewe bydrae tot die voorkoming van mishandeling by kinders kan maak. Voorkoming is altyd 'n spanpoging en in hierdie geval 'n spanpoging by uitnemendheid. Die verpleegkundige het egter 'n sleutelrol in hierdie span omdat sy in die voorste linie staan. Om hierdie rol optimaal te kan vertolk moet die verpleegkundige en veral die vroedvrou en gemeenskapsverpleegkundige die nodige kennis hê om haar sensitief te maak vir moontlike gevaartekens, moet sy die nodige bystand en voorligting aan ouers kan gee en moet sy weet waarheen sy risiko-ouers kan verwys vir verdere hulp, bystand en terapie. Sy moet dus die ander lede van die span ken die maatskaplike werkster, die geneesheer, die predikant, die psigiatriese span - sy moet weet wat elkeen se rol is sodat sy nou met hulle kan saamwerk en sy moet bewus wees van gespesialiseerde hulpbronne wat in die gemeenskap beskikbaar is.

Die term gebeukte kind of mishandelde kind (Battered Child) word gegee aan 'n jong kind wie se liggaampie gekneus is, met frakture en brandwonde veroorsaak deur die optrede van een of beide ouers. Hierdie fisiese letsels gaan dikwels gepaard met algemene verwaarlosing en wanvoeding veral in die lae sosio-ekonomiese groepe. Bewyse vir die ouer se aandeel is nie altyd maklik te kry nie maar 'n onbetroubare en teenstrydige weergawe van die omstandighede wat gelei het tot die besering en 'n onvermoë om 'n redelike verduideliking vir die skade aan die kind te gee wek die suspisie. Getuies van die bure lei tot bevestiging van die suspisie.

Navorsing het getoon dat ouers wat hulle kinders mishandel nie aan 'n spesifieke persoonlikheidstipe, intelligensiegroep of sosiale klas behoort nie. Hulle het bevind dat dit niks te doen het met ras of kleur, inkomstegroep, onderwyspeil of enigiets anders nie. Daar is wel studies veral deur Smith, Hanson en Noble wat toon dat die insidensie van kindermishandeling hoër is by sekere groepe soos bv. baie jong ouers van 'n lae sosiale stand, persone met psigiatriese afwykings en met 'n subnormale intelligensie en dat dit verband hou met alkoholisme en kriminaliteit. Die meeste navorsers kom egter tot die gevolgtrekking dat mishandelaars (batterers) normale persone is wat om een of ander rede onder groot druk verkeer. Kempe (1972) beskou elke ouer as 'n potensiële "batterer'".

As ons dus aanvaar dat daar wel omstandighede is wat van 'n ouer 'n risiko-ouer t.o.v. mishandeling maak kan ons met riglyne verskaf deur die navorsers wel hierdie ouers identifiseer en van die nodige hulp, bystand en terapie verseker om moontlike mishandeling te probeer voorkom. Dit kan 'n sensitiwiteit wek wat so broodnodig is vir sinvolle optrede en verwysing na die nodige hulpbronne. 
Die volgende gevalle wat reeds in die voorgeboorte geskiedenis opgestel kan word blyk belangrik genoeg te wees om aan te teken:

- 'n moeder onder die ouderdom van 20 jaar by die geboorte van haar eerste kind; (Smith 1973)

- 'n moeder of vader met 'n psigiatriese geskiedenis van gediagnoseerde neurose of van gediagnoseerde persoonlikheidsgebreke; (Smith 1973)

- 'n moeder met 'n lae of subnormale intelligensie; (Smith 1973)

- 'n moeder of vader met 'n kriminele rekord; (Smith 1973)

- 'n moeder met 'n geskiedenis van swak gesondheid; (Smith 1973)

- 'n ongehude moeder; (Smith 1974)

- 'n kind wie se natuurlike vader nie by die moeder bly nie; (Smith 1974)

- ouers wat mekaar minder as 6 maande voor die huwelik geken het; (Smith 1974)

- ouers waarvan die kind verwek is voor die huwelik; (Smith 1974)

- waar die moeder dink die vader verwerp die kind en of waar die moeder self die idee van die kind verwerp; (Smith 1974)

- die moeder beskou die huwelik as onsuksesvol; (Smith 1974)

- die moeder sien selde haar eie ouers of ander familie en het geen eie vriende nie. Lei 'n baie eensame lewe; (Smith 1974)

- daar is tekens van finansiële nood - die behuising is onvoldoende - die vader verdien baie min of is werkloos - die moeder moet werk om kop bo water te hou en is bekommerd dat sy sal moet ophou werk as die baba kom; (Smith 1974)

- die moeder is oor die algemeen ontevrede met haar lot; (Smith 1974)

Die navorsers (Smith 1975) het ook ingegaan op die invloed van die verhouding van die ouers met hulle ouers en familie en bevind dat die verhoudings besliste risiko's skep. Die navorsing sluit ook aan by dié van Frommer en O'Shea (1973) waar bewys is dat waar daar 'n verwydering tussen die moeder en haar eie moeder was die kanse groot is dat sy probleme sal ondervind met die grootmaak van haar kind.

Aspekte wat in die verband risiko's skep is:

- die moeder getuig van ongelukkige kinderjare en

het oor die algemeen nie goed met haar ouers of

broers en susters klaar gekom nie - sy kom steeds nie met hulle klaar nie; (Smith 1975)

- die moeder dink dat haar moeder en/of vader onredelik was in hul dissipline en dieselfde geld vir die vader se ouers; (Smith 1975)

- die moeder dink dat sy 'n swak skolier was en het reeds een of meer neurotiese neigings as kind openbaar; (Smith 1975)

- uit die gesprek blyk dit duidelik dat die moeder leuens vertel; (Smith 1975)

- die moeder is baie krities teenoor almal om haar en openbaar 'n paranofese vyandigheid ook teenoor kliniekpersoneel en veral teenoor vrae sy woon die voorgeboorte kliniek ongereeld of gladnie by nie en daag ook nie by moederkunde klasse op nie; (Smith 1975).
Aspekte wat nageboorte by die versorging en hantering van die kind aandag verdien en wat reeds in die puerperiumsaal daarna in die nageboortekliniek waargeneem word is deur Smith (1975) as risiko's geïdentifiseer:

- die moeder is abnormaal - d.w.s. te vinnig of baie stadig in haar respons tot die baba se huil;

- die moeder word emosioneel oor voedingsprobleme

- daar is tekens van 'n gebrek aan moeder/kind kontak bv. oog-tot-oogkontak word nie gemaak nie;

- sy toon geen of weinig emosies teenoor haar kind;

- sy "geniet" nie haar baba nie;

- sy is wisselvallig in haar besorgdheid oor die welsyn en welstand van haar kind - een dag traak-my-nie-agtig en die volgende oorbeskermend;

- die moeder en/of vader is onverbiddellik t.o.v. gehoorsaamheid en een of beide tug dikwels fisies;

- die moeder weerhou haar liefde en liefkosings van die kind as strafmaatreël en gee slegs materiële beloning soos lekkers vir goeie gedrag;

- die huil van die baba of die klou en kla van die kleuter skep geweldige reaksie en probleme vir die moeders

- die vader help nie met die kind soos die moeder verwag het nie;

- daar is skynbaar nooit besprekings tussen moeder en vader oor die opvoeding van die kind nie;

- daar is tuis weinig privaatheid en die kind het nie 'n eie kamer nie. Die moeder en vader is dus nooit alleen nie;

- die moeder het geen sosiale aktiwiteite nie;

- die moeder verwerp openlik die kind.

Martin (1976) gaan verder en bewys dat die volgende faktore die kanse van mishandeling sal vergroot as die ouer boonop 'n hoë neiging het om 'n mishandelende ouer te word:

- ernstige faktore wat die vroeë moeder-kind-kontak versteur soos bv. prematuriteit of skeiding van die moeder en die pasgeborene vir watter rede ookal;

- eienskappe in die kind wat hom 'n minder erkentlike kind maak, 'n kind wat hoë esse aan 'n ouer stel. Dit kan 'n normale kind wees met voedingsprobleme of 'n kind wat ontroosbaar huil. Of dit mag 'n kind wees met geringe neurologiese disfunksie wat tipies minder erkentlik is en moeilik versorg word. Of dit kan 'n kind wees met 'n subnormale intelligensie;

- enige kind wat nie aan die verwagtings van die ouer voldoen nie. Dit kan eenvoudig 'n saak wees soos 'n kind van die "verkeerde"' geslag of meer dikwels 'n normale kind waarvoor die ouers onrealistiese en soms verwronge verwagtings koester. Dit kan ook 'n kind wees wat vanaf geboorte siek is of wat een of ander gebrek het;

- die ontwikkelingsvlak van die kind mag vir die ouer 'n stremmingstoestand skep. So kan die eise van 'n hulpelose baba vir een ouer meer stremmingvol wees terwyl die ander ouer die nuuskierige, praterige voorskoolse kleuter nie kan "vat" nie.

As 'n mens aanvaar dat sommige persone vanweë genoemde omstandighede 'n hoë risiko loop om 
mishandelende ouers te word kan daar beslis voorkomend opgetree word.

\section{Voorkoming van swangerskap}

Voorligting i.v.m. gesinsbeplanning om die onwelkome, onbeplande swangerskap te voorkom is belangrik en behoort binne die bereik van elke persoon te wees. Dit is ook belangrik dat jongmense voorligting oor verantwoordelike ouerskap op 'n vroeë leeftyd ontvang sodat hulle nie alleen voorbereid kan wees op hulle baie belangrike rol as ouers nie maar om hulle bewus te maak van die verantwoordelikheid wat ouerskap bring en die soms katastrofiese gevolge van promiskuiteit.

Die psigiatriese verpleegkundige het ook 'n besondere rol waar sy kontak het met baie jong, vrugbare geestesversteurde persone. Sy is bewus van hulle agtergrond-geskiedenis en of hulle as kinders mishandel was. Sy kan tussentrede beplan en voorligting gee oor gesinsbeplanning. As so 'n pasiënt ontslaan word moet sy die maatskaplike werkster op haar hoede stel. Kontak moet met die persoon behou word en indien swangerskap voorkom moet daar noue skakeling wees met die voorgeboorte en na-geboorte dienste, sodat die nodige opvolgsteun gegee kan word.

\section{POGINGS TOT VOORKOMING IN DIE VOORGEBOORTE TYDPERK}

\section{Identifikasie van risiko-ouers}

Eerstens moet die risiko-ouer of gesin geïdentifiseer word en die rol van die vroedvrou en gemeenskapsgesondheidsverpleegster is hier kardinaal. Hulle is beide in ' $n$ unieke posisie in hulle kontak met ouers, ongeag die se sosiale stand, om tekens van spanning en die depressie waar te neem en hulp en bystand te gee of om die nodige verwysings na ander lede van die span te maak indien nodig.

In Johannesburg waar daar 'n "Mishandelde KindKliniek" bestaan word die grootste aantal verwysings vir primêre voorkoming gedoen deur vroedvroue vanaf die naby geleë kraamhospitale se voorgeboorte kliniek. Dit is gewoonlik gevalle van depressie veroorsaak deur 'n onwelkome swangerskap, vrees vir swangerskap gewoonlik a.g.v. een of ander mediese probleem en die moeder se vrees vir haar eie onvermoë om 'n kind te hanteer.

Verdere verwysings is ongehude moeders wat wik en weeg of hulle die baba moet hou of nie en van moeders met psigiatriese probleme. 'n Noue kontak bestaan ook met die gemeenskapsgesondheidsverpleegsters veral in gevalle van moeders met voedingsprobleme of waar die baba skynbaar nie vorder nie.

Hierdie kliniek gebruik aan die ander kant weer die gemeenskapsgesondheidsverpleegster om gesinne waar mishandeling reeds plaasgevind het op te volg na behandeling of om gesinne wat "verdwyn" te probeer opspoor. Die gemeenskapsgesondheidsverpleegster wat haar area ken weet van elke nuwe intrekker en haar verhouding met die gesinne in die gemeenskap is van so 'n aard dat sy probleemgesinne vinnig "optel"'. Sy leer om gevaar te ken en vinnig raak te sien. Dit gee haar die geleentheid om onverwyld haar suspisies met die geneesheer of maatskaplike werkster te bespreek vir moontlike optrede.
Goeie skakeling tussen die hospitaal en die gesondheidsverpleegster is ook noodsaaklik. Die ongevalle-afdeling behoort enige besering aan ' $n$ kind wat nie deur 'n motorongeluk veroorsaak is nie aan die gemeenskapsgesondheidsverpleegster van die area te rapporteer. Sy kan die geval opvolg en indien dit 'n geval van 'n ongeluk by die huis was onverwyld die nodige voorligting oor die voorkoming van ongelukke tuis gee. Indien wel 'n geval van mishandeling raadpleeg sy die maatskaplike werkster wat statutêre magte onder die Kinderwet het om op te tree in belang van die kind.

\section{Skep van 'n vertrouensverhouding}

Om hulp en bystand te gee moet daar 'n vertrouensverhouding tussen die verpleegkundige en die moeder opgebou word deur gereelde, vriendelike kommunikasie. Benewens die fisiese ondersoek by die voorgeboorte kliniek kan die noodsaaklikheid van kommunikasie met die moeder nie oorbeklemtoon word nie. 'n Moeder moet nooit die indruk kry dat sy slegs 'n liggaam is waarin 'n foetus groei nie. Sy het 'n behoefte aan inligting en haar belangstelling in die groeiende baba in haar moet bevredig en versterk word deur iemand met die nodige kennis en die regte gesindheid. Drukte van werk en wisseling van personeel veroorsaak groot leemtes in dié verband. Dit is egter die plig van die organiseerder van voorgeboorte klinieke om leemtes op te vang en onnodige kommunikasiegapings uit te skakel.

Daar is ook ' $n$ al groter wordende bewustheid vir die psigososiale behoeftes van die swanger vrou wat beduidende veranderinge in die houding en benadering van beide geneesheer en vroedvrou noodsaak. Navorsing het getoon dat aandag aan dié behoeftes lei tot nouer kontak ("bonding"') tussen moeder en baba wat onder andere die kanse van kindermishandeling verminder.

\section{Ouerkunde klasse}

Klasse word tans by elke goedgeorganiseerde voorgeboorte eenheid aangebied maar neem meestal die vorm aan van slegs moederkunde-klasse. Die klem val ook meestal op die fisiese versorging en voeding van moeder en kind. Klem op die psigososiale aspekte wat die gesin raak en die moeder-kind verhouding laat dikwels veels te wense oor (Schneider 1979) en moet aandag kry. Een van die mees belangrike aspekte in die voorkoming van kindermishandeling is die ontwikkeling van 'n gesinsgevoel so vroeg as moontlik in swangerskap. Die insluiting van die vader in ouerkunde klasse moet dus meer aandag kry.

Dit is algemeen bekend dat die moeder wat belangstel en omgee meer dikwels dié klasse bywoon en dat dit juis die moeder is wat ' $n$ potensiële mishandelaar is wat wegbly. Elke moontlike poging en skakeling met gemeenskapshulpbronne moet dus aangewend word om juis die moeder en vader by die ouerkundeklasse te betrek. Navorsing het bewys dat goeie ouerskap deur voorligting geleer kan word (Reynolds).

\section{Die invloed van die Tegnologie}

Tegnologiese vooruitgang het veroorsaak dat 'n veelheid van metodes om die toestand van die baba gedurende swangerskap en die bevalling te monitor aan 
die orde van die dag is. Indien die moeder nie sorgvuldig in eenvoudige terme ingelig is oor wat gebeur nie, bestaan die gevaarlike moontlikheid dat sy haarself totaal verwyderd kan voel van die ontwikkeling van haar baba en kan die blote meganika van die hantering van die swangerskap dreig om die menslike aspekte van die versorging van die moeder te oorskadu.

As gevolg van dié metodes word die lewens van babas gered wat intensiewe behandeling en versorging lank na die bevalling nodig het. Juis die groep loop 'n hoë-risiko vir latere mishandeling. Dit kan wees dat sorgvuldige verduideliking reeds vroeg in die swangerskap van wat na die geboorte sal gebeur, probleme van mishandeling kan uitskakel (Anderson).

\section{Die Bevalling}

Onnodig om te sê dat die voorbereiding van die moeder vir die bevalling so volledig moontlik moet wees. Benewens ' $n$ verduideliking van die fisiologiese gebeure moet die moeder ook bekend gestel word met die hele battery van toerusting wat in die kraamsaal op haar wag. Die tegnieke en redes vir induksies, die kardiotokogram, ens, ens. kan alles heel eenvoudig selfs aan 'n minder intelligente verduidelik word en kan vrees beperk (Anderson).

Die vroedvrou moet ten alle koste waak dat die geboorteproses ontaard in ' $n$ fyn beplande en tegniese korrekte wetenskaplike prosedure. Die moeder moet die fokuspunt bly en moet die geleentheid gegun word om onmiddellik na geboorte optimale kontak met haar baba te maak. Indien dit onvermydelik nie kan gebeur nie moet sy gerusgestel word en die redes aan haar verduidelik word sodat sy betrokke kan bly. Die vader moet tydens die bevalling in die prentjie gehou word indien hy nie teenwoordig kan wees nie en hy moet ten alle koste voel dat hy deel van die hele proses is. Die gesinsverband word hierdeur versterk.

\section{DIE PUERPERIUM}

Veral drie aspekte verdien hier aandag:

\section{Borsvoeding}

Borsvoeding wat in die voorgeboorteperiode reeds aangemoedig moet word, moet die nodige aandag en toesig kry. Geen groter kontak kan tussen moeder en baba bewerkstellig word as juis deur borsvoeding nie. Aan die anderkant is dit belangrik dat ' $n$ moeder wat om watter rede ookal, nie wil of kan borsvoed nie nooit met 'n skuldgevoel gelaat word nie.

\section{Depressie}

Waarneming van tekens van depressie by die risikomoeder en die nodige ondersteuning en verwysing na ' $n$ psigiatriese kliniek is van uiterste belang vir die nodige terapie. Die gewone depressie van enige moeder moet egter nie afgemaak word asof van geen belang nie veral nie as dit die vorm aanneem waar die moeder die baba ignoreer of verwaarloos nie (Lynch).

\section{Skeiding van moeder en baba}

Navorsers het getoon dat dit een van die grootste bydraende faktore is tot die mishandeling van kinders.
Ouers moet ingelig word oor die toestand van hulle baba en moet aangemoedig word om met verpleegkundiges en die geneesheer te praat, moet die geleentheid kry om die baba gereeld te besoek en moet indien moontlik die baba hanteer en voed. Die moeder veral het baie steun nodig "Mother the mother" (Howat). Aan die anderkant moet daar opgelet word of die moeder wel die baba besoek en hoe dikwels, wat haar houding teenoor die kind is; is sy belangstellend, vra sy hoe dit gaan, wil sy die baba hanteer (Howat, Lynch).

\section{Die na-geboorte tydperk}

Die gemeenskapsgesondheidsverpleegster dra kennis van elke nuwe geboorte in haar area.

Haar verhouding met die personeel van die hospitaal waar die moeder vir voorgeboortesorg en vir die bevalling gegaan het moet van so 'n aard wees dat sy reeds voor ontslag van die moeder uit die hospitaal bewus is van 'n moontlike risiko vir mishandeling in die gesin.

Sy kry die geleentheid om elke moeder tuis in haar eie omgewing te besoek, om werklik 'n persoonlike verhouding van vriendskap op te bou en om dus gevaartekens vroegtydig te identifiseer.

Moeders wat versuim om na die na-geboorte kliniek te gaan moet opgevolg word. Die verpleegkundige behoort ook 'n besondere verhouding met privaatgeneeshere op te bou sodat so 'n geneesheer haar hulp sal inroep om 'n moeder of gesin op te spoor wat versuim om hom na die geboorte te besoek.

In die baba-kliniek het sy die geleentheid om die moeder noukeurig waar te neem in haar hantering van die baba, haar van die nodige hulp en leiding te voorsien en die eerste tekens van verbreking van kontak tussen moeder en kind raak te sien.

\section{Samevatting}

Die verpleegkundige en veral die vroedvrou en gemeenskapsgesondheidsverpleegster kan 'n groot bydrae lewer in die voorkoming van mishandeling by kinders deur 'n sensitiwiteit te ontwikkel vir die bydraende faktore wat van 'n ouer 'n potensiële mishandelaar maak, hierdie ouers te help identifiseer, die nodige hulp en leiding te gee en die regte verwysings te maak waar nodig.

\footnotetext{
Bronnelys:

1. Bowley, Agatha H. (1975): Children at risk. London, Churchill Livingstone.

2. Franklin, Alfred W. (ed) (1977): Child Abuse: prediction, prevention and follow up. London. Churchill Livingstone.

- Anderson, Mary: Prediction and prevention - an obstetrician's view. - Reynoids, Cynthia: Can good parenting be taught?

- Hanson, McCullough, W. and Hartley, S.: Key characteristics of child abuse.

- Lynch, M. and Roberts, J.: Early alerting signs.

- Howat, Pamela: $A$ nurse's observations on mothers and babies in a special care baby unit.

3 . Frommer E.A. \& O'Shea, G. (1973): British Journal of Psychiatry. 123. 149-56.

4. Kempe, C.H. \& Helfer, R.E. (1972): Helping the Battered Child and his family. Philadelphia. Lippincott.

. Kempe, C.H. \& Helfer, R.E. (1976): Child abuse and neglect in the family and the community. CL4. Cambridge. Ballinger

6. Schneider: Education for parenthood. The experience of primagravidae. Ongepubliseerde M.Ed. verhandeling. RAU.

Smith, S.M. (1975): The battered child syndrome. London. Butterworths.

7. Smith, S.M. (1975): The battered child syndrome. London. Butterworths.
8 Smith, S.M. \& Hanson, R. \& Noble, S. (1973): Parents of battered babies: a controllSmith, S.M. \& Hanson, R. \& Noble, S. (1973):
ed study. British Medical Journal, 4, 380-391.

9. Smith, S.M. \& Hanson, R. \& Noble, S. (1974): Social aspects of the battered baby syndrome. British Journal of Psyschiatry, 125, 568-582.

10 Smith, S.M \& Hanson, R. (1974): 135 Battered children: a medical and psychologica study. British Medical Journal. 3, 666-670.

1 Smith, S.M. \& Hanson, R. (1975): Interpersonal relationships in 214 parents of battered children. British Journal of Psychiatry. 127, 513-525,
} 